Revista de Derecho YACHAQ

ISSN: 1817-597x (impresa) / ISSN: 2707-1197 (en linea)

Centro de Investigación de los Estudiantes de Derecho (CIED)

Universidad Nacional de San Antonio Abad del Cusco

N. ${ }^{\circ} 10-2019$

[pp. 153-164]

Fecha de recepción: 06/08/19

Fecha de aceptación: 13/09/19

\title{
Caducidad en el procedimiento administrativo sancionador y su aplicación distinta en los diferentes órganos resolutivos del Indecopi
}

\section{Expiration in the Procedure of the Administrative Sanctions and in its Different Application in the Different Resolution Bodies Of INDECOPI}

\author{
Alexander Walter Flores Marin ${ }^{[*]}$
}

\begin{abstract}
RESUMEN: la Caducidad administrativa es una figura existente en el Derecho Administrativo Sancionador que busca resguardar el equilibrio entre el deber de impulsar el procedimiento de la autoridad y del derecho de los administrados, cuando se encuentren sometidos a algún procedimiento gravoso, a contar con un plazo razonable para la determinación de infracciones y sanciones.

Sin embargo, pese a que esta institución fuera introducida en la normativa peruana en el año 2016, con reglas claras para su aplicación, el INDECOPI, a través de diferentes pronunciamientos emitidos por sus diferentes órganos de resolución, ha realizado disímiles interpretaciones, incluso, contradictorias, de la manera en la que esta figura debe aplicarse (o no aplicarse). Así, el autor realiza un análisis de los criterios emitidos por esta entidad para posteriormente emitir su valoración final sobre los elementos necesarios para aplicar la caducidad.

ABSTRACT: the administrative Expiration is an existing figure in the Administrative Sanctions Procedure that seeks to safeguard the balance between the duty to promote the procedure of the Authority and the rights of the administrated ones, when they are subject to some burdensome procedure, have to have a reasonable period for the determination of the infractions and penalties.

However, despite the fact that this institution was introduced in the Peruvian regulations in 2016 with clear rules for its application, INDECOPI through different pronouncements issued by its different resolution bodies, has made different interpretations, even contradictory, in the
\end{abstract}

[*] Abogado por la Universidad Nacional Mayor de San Marcos. Cursa estudios de postgrado en la Maestría de Derecho de la Empresa de la misma casa de estudios. Ha sido becario del XIX Curso de Extensión Universitaria en regulación con especialización en Telecomunicaciones. Actualmente, forma parte del equipo de Competencia del Estudio Muñiz, Olaya, Meléndez, Castro, Ono y Herrera.

Contacto: afloresm@munizlaw.com 
manner of how this figure should be applied (or not applied). In this way the author performs an analysis of the criteria issued by this entity to subsequently issue its final assessment about the necessary elements to apply this institution.

Palabras Clave: derecho Administrativo Sancionador; Caducidad; INDECOPI; protección al consumidor; competencia desleal.

Keys Words: administrative Sanctions Procedure, expiration; INDECOPI; consumer protection; unfair competition.

\section{INTRODUCCIÓN}

El 21 de diciembre de 2016 se publicó en el diario oficial El Peruano el Decreto Legislativo N. ${ }^{\circ} 1272$, por el cual se modificó la Ley N. ${ }^{\circ} 27444$, Ley del Procedimiento Administrativo General, realizando múltiples modificaciones e incorporando nuevas disposiciones. Entre estas nuevas disposiciones se implementó con carácter general la institución de la Caducidad en los procedimientos Administrativos Sancionadores ${ }^{[1]}$.

Así, al incorporar esta figura de la Caducidad administrativa, se buscó el equilibrio del ius puniendi del Estado (a nivel administrativo) y los derechos de los sujetos administrados a contar con un plazo razonable para la determinación de infracciones y sanciones por parte de la autoridad. Para cumplir con dicho cometido, se fijó los elementos generales para el cumplimiento de la caducidad, los cuales debían ser cumplidos por todas las instituciones administrativas.

En ese sentido, es importante verificar como el INDECOPI, institución altamente especializada y técnica, que tiene a su cargo diferentes procedimientos administrativos (concursal, libre competencia, competencia desleal, protección al consumidor y otros) de vital relevancia para nuestra sociedad y que sirve de guía para otras entidades administrativas, ha venido aplicando esta figura en los diferentes procedimientos a su cargo.

Así, en el presente trabajo, realizaremos una revisión de las decisiones emitidas por tres órganos distintos del INDECOPI en el último año: Comisión de Protección al Consumidor N.$^{\circ}$ 2; la Sala especializada en Protección al Consumidor y la Sala especializada en Defensa de la Competencia. Estas tres áreas emblemáticas del INDECOPI han considerado diferentes criterios al momento de emitir sus resoluciones finales, para la aplicación de la caducidad administrativa, conforme verificaremos más adelante.

\section{SOBRE LA CADUCIDAD Y SU INCORPORA- CIÓN AL ORDENAMIENTO PERUANO}

En el Decreto Legislativo N. ${ }^{\circ} 1272$ no se introdujo una definición para la Caducidad; sin embargo, esta figura ya se encontraba reconocida en la doctrina española. Así, la Caducidad «Es una válvula de seguridad introducida en los procedimientos administrativos que permite darlos por terminados cuando quien los promueve pierde interés en los mismos» (Gonzales y Gonzales, 2012, p.2307). Asimismo, complementa Caballero (1999), «Esta pérdida de interés se mide por el dato objetivo de la falta de actuaciones en determinados plazos» (p. 169).

Complementariamente, para el profesor Gonzales (2002) «La caducidad es un hecho jurídicoadministrativo, no un acto: Su eficacia jurídico- administrativa no tiene en cuenta la voluntad, sino el transcurso del plazo señalado por la ley» (p. 365).

Adicionalmente, ya en el 2011 el profesor Baca mencionaba lo siguiente ${ }^{[2]}$ :

La caducidad perención, por la cual se extinguen los procedimientos por inactividad, ya sea

[1] En la exposición de motivos del mencionado Decreto Legislativo N..$^{\circ}$ 1272, se precisó que esta incorporación era realizada «en aras de preservar condiciones básicas de seguridad jurídica, se establecen ciertas pautas a seguir que buscan cerrar una situación para que esta no quede indefinidamente sin una solución definitiva».

[2] Cabe indicar que el profesor Baca Oneto, además de dictar diferentes cátedras de Derecho Administrativo, ha sido comisionado de diferentes órganos resolutivos del INDECOPI. Cabe indicar que dicho artículo fue elaborado cuando aún no se había introducido la figura de caducidad en la normativa peruana. 
del administrado en los procedimientos iniciados a pedido de parte (supuesto regulado en el art. 191 LPAG) como de la Administración en los procedimientos iniciados de oficio, como es el caso de los procedimientos sancionadores. Esta última no ha sido regulada en el derecho peruano, pese a que sí lo está en el derecho positivo español [...] (pp. 265-266).

En ese sentido, podemos concluir que «La caducidad es la forma de terminación del procedimiento administrativo por superación del plazo máximo para resolver, cuyo cumplimiento impide su prosecución y resolución final» (Caballero, 2010, p. 799).

Cabe indicar que el Ministerio de Justicia del Perú (2017) indicó que «La caducidad del procedimiento sancionador constituye una solución generada por el legislador para afrontar los casos en los que los procedimientos iniciados por los órganos competentes quedan paralizados afectando los derechos de los administrados involucrados» (p. 54).

En tal sentido, la razón para incorporar la figura de la Caducidad Administrativa en el ordenamiento para los procedimientos sancionadores está en la necesidad de no prolongar indefinidamente situaciones expectantes de posibles sanciones; lo cual atenta contra el administrado y contra sus derechos fundamentales a ser investigado en un plazo razonable; asimismo, poner un límite al ius puniendi administrativo del Estado, a través de sus diferentes órganos administrativos, cuando pierden interés en concluir sus investigaciones en un plazo razonable ${ }^{[3]}$.

Ahora bien, tal como se indicó anteriormente, mediante el Decreto Legislativo $N .^{\circ} 1272$ se introdujo en nuestro ordenamiento jurídico de forma general, siendo aplicable a todos los procedimientos administrativos sancionadores la institución de la Caducidad conforme lo siguiente:
Artículo 237-A. Caducidad del procedimiento sancionador

1. El plazo para resolver los procedimientos sancionadores iniciados de oficio es de nueve (9) meses contado desde la fecha de notificación de la imputación de cargos. Este plazo puede ser ampliado de manera excepcional, como máximo por tres (3) meses, debiendo el órgano competente emitir una resolución debidamente sustentada, justificando la ampliación del plazo, previo a su vencimiento. La caducidad no aplica al procedimiento recursivo.

Cuando conforme a ley las entidades cuenten con un plazo mayor para resolver la caducidad operará al vencimiento de este.

2. Transcurrido el plazo máximo para resolver, sin que se notifique la resolución respectiva, se entiende automáticamente caducado el procedimiento y se procederá a su archivo.

3. La caducidad es declarada de oficio por el órgano competente. El administrado se encuentra facultado para solicitar la caducidad del procedimiento en caso el órgano competente no la haya declarado de oficio.

4. En el supuesto que la infracción no hubiera prescrito, el órgano competente evaluará el inicio de un nuevo procedimiento sancionador. El procedimiento caducado no interrumpe la prescripción.

Asimismo, a efecto de establecer una correcta aplicación de la caducidad administrativa a los procedimientos administrativos sancionado-

[3] En este contexto, como un antecedente importante del plazo razonable, desarrollada en el Perú por la jurisprudencia, fue la Sentencia expedida por el Tribunal Constitucional el 19 de octubre de 2009, en el Expediente N. ${ }^{\circ}$ 3509-2009-PHC/TC (Lima, Walter Gaspar Chacón Málaga), en la que dicho organismo afirmó que «el derecho a ser juzgado en un plazo razonable constituye una manifestación implícita del derecho al debido proceso». Es decir, ya en ese entonces era evidente para la autoridad que por más complejidad que pueda presentar un caso, no hay razón para dilatar un procedimiento más allá de su plazo legal para mantener en incertidumbre a un procesado o administrado. 
res que se encontraban en trámite ${ }^{[4]}$, dicho Decreto Legislativo estableció (en su Quinta Disposición Complementaria Transitoria) un plazo de aplicación distinto para estos últimos:

Quinta. Para la aplicación de la caducidad prevista en el artículo 237-A de la Ley N.ㅇ 27444, Ley del Procedimiento Administrativo General, se establece un plazo de un (1) año, contado desde la vigencia del presente Decreto Legislativo, para aquellos procedimientos sancionadores que a la fecha se encuentran en trámite.

Así, el régimen general de la Caducidad administrativa se encuentra contenida en estas normas $^{[5]}$, las cuales son aplicables desde la vigencia del Decreto Legislativo N. ${ }^{\circ} 1272$. En ese sentido, es posible identificar las reglas establecidas como generales para la aplicación de la caducidad administrativa en los procedimientos administrativos sancionadores en el ordenamiento peruano:

1) Se estableció una regla transitoria para aquellos procedimientos administrativos sancionadores que se encontraban en trámite antes de la entrada en vigencia del Decreto Legislativo N. ${ }^{\circ}$ 1272: El plazo de caducidad sería de un año, contado a partir de la entrada en vigencia del mencionado Decreto Legislativo.

2) La regla general de los procedimientos administrativos sancionadores (iniciados luego de la vigencia del Decreto Legislativo N. ${ }^{\circ}$ 1272) se encuentran sujetos a un plazo de caducidad de nueve meses, ampliables por tres meses más, siempre que se emita una resolución motivando dicha ampliación. Asimismo, las leyes especiales pueden determinar un plazo mayor de caducidad.

3) Las características de la caducidad administrativa son las siguientes:
- Únicamente aplicarán a procedimientos sancionadores iniciados de oficio.

- Transcurrido el plazo máximo para resolver, sin que se notifique la resolución correspondiente, se entenderá automáticamente caducado el procedimiento.

- La caducidad administrativa debe ser declarada de oficio por el órgano correspondiente.

- La resolución es emitida con posterioridad a los nueve meses (o doce meses, de corresponder), tendrá un carácter declarativo, en tanto la caducidad opera automáticamente.

- El administrado puede solicitar la caducidad administrativa; sin embargo, la obligación de emitir la resolución de caducidad sigue perteneciendo al órgano correspondiente.

- El procedimiento administrativo caduco no interrumpe la prescripción.

- No aplica la caducidad administrativa para los procedimientos recursivos.

- Un procedimiento especial podría establecer un plazo mayor al de los nueve meses para la aplicación de la caducidad administrativa.

Pese a lo anterior y a las reglas claras establecidas en el Decreto Legislativo N. ${ }^{\circ} 1272$, el INDECOPI ha realizado hasta tres interpretaciones distintas sobre la aplicación de la caducidad, a través de sus diferentes órganos: Comisión de protección al Consumidor N. ${ }^{\circ}$ 2; la Sala especializada en Protección al Consumidor y la Sala especializada en Defensa de la Competencia. Las cuales detallamos a continuación.

[4] A la entrada en vigencia del Decreto Legislativo N. ${ }^{\circ}$ 1272, existían procedimientos administrativos sancionadores en trámite, por lo que se dispuso una medida razonable para la correcta aplicación de la caducidad administrativa a estos casos.

[5] Posteriormente, se emitió el Decreto Supremo 004-2019-JUS en el que se aprobó el Texto Único Ordenado de la Ley 27444 , siendo que se identificó a estas disposiciones en el artículo 257 y en la disposición complementaria décima. 


\section{SOBRE EL CRITERIO PARA LA APLICACIÓN DE LA CADUCIDAD EN LOS PROCEDIMIEN- TOS DE PROTECCIÓN AL CONSUMIDOR Y COMPETENCIA DESLEAL SEGUIDOS ANTE EL INDECOPI}

Entre las facultades de competencia del INDECOPI se encuentra la protección de los derechos de los consumidores, los cuales se encuentran contenidos en la Ley N. . $^{\circ}$ 29571, Código de protección y defensa del Consumidor (y normas conexas). Así, el INDECOPI supervisa el mercado, verificando que los proveedores de productos y servicios cumplan con las disposiciones y derechos garantizados a los consumidores, en el marco de una relación de consumo; en caso de verificar un incumplimiento, puede iniciar un procedimiento administrativo sancionador, contando con la facultad para imponer sanciones y medidas correctivas a los proveedores que hayan cometido alguna infracción al mencionado Código.

Sobre el particular, el INDECOPI cuenta con una estructura interna en la que dependiendo de la característica de la materia y/o cuantía ha dispuesto las vías para canalizar las denuncias por presuntas infracciones al Código; así, tenemos como órganos de primera instancia administrativa: Órgano Resolutivo de Procedimiento Sumarísimo (1, 2 y 3$)$ y a la Comisión de Protección al Consumidor ${ }^{[6]}(1,2$ y 3); cabe indicar que el INDECOPI también cuenta con órganos descentralizados a nivel nacional; asimismo, como órgano de segunda instancia administrativa a la Sala Especializada en Protección al Consumidor.

Complementariamente, el INDECOPI también tiene a su cargo la represión de todo acto que tenga por efecto afectar o impedir el adecuado funcionamiento del proceso competitivo; asimismo, las infracciones a las normas que regulan la publicidad comercial. Estas disposiciones se encuentran en el Decreto Legislativo N. ${ }^{\circ}$ 1044, Ley de Represión de la Competencia Desleal. Respecto a la estructura interna para canalizar los procedimientos administrativos sancionadores, la primera instancia es la Comisión de Fiscalización de la Competencia Desleal y la segunda instancia es la Sala Especializada en Defensa de la Competencia.

Realizado este pequeño resumen, en los párrafos siguientes analizaremos tres resoluciones emitidas por el INDECOPI, específicamente, por la Comisión de Protección al Consumidor N. ${ }^{\circ}$ 2; la Sala Especializada en Protección al Consumidor y la Sala Especializada en Defensa de la Competencia, a efectos de verificar cómo estos tres diferentes órganos, pese a su cercanía física, mantienen criterios distintos sobre la aplicación de la figura de la caducidad administrativa.

\subsection{Resolución Final $\mathrm{N}^{\circ}{ }^{\circ} \mathbf{2 4 5 6 - 2 0 1 8 / C C 2}$}

Al respecto, mediante la Resolución Final N. ${ }^{\circ} 2456-2018 / C C 2^{[7]}$, de fecha 23 de octubre de 2018, la Comisión de Protección al Consumidor N. ${ }^{\circ} 2$ emitió la Resolución Final correspondiente a la denuncia interpuesta por la Asociación Peruana de Consumidores y Usuarios (ASPEC) en contra de Inmobiliari S.A.; Edificaciones y construcciones El Agustino y Carlos Mario Vargas Montoya.

Dicho procedimiento fue originado por presuntas infracciones en los departamentos construidos por los denunciados. Así, con fecha 26 de enero de 2017 fueron notificados los denunciados con la resolución de inicio del procedimiento administrativo sancionador; sin embargo, transcurridos nueve meses (esto es el 26 de octubre de 2017) no se había notificado la resolución que pusiese fin al procedimiento, por lo que con fecha 21 de septiembre de 2018 (más de 2 años después) los denunciados solicitaron que se aplique la caducidad del procedimiento.

La Comisión de Protección al Consumidor N. ․ 2 declaró la caducidad del procedimiento, mediante la Resolución Final; sin embargo, desarrolló el siguiente criterio para la aplicación de dicha figura:

1. Los procedimientos administrativos sancionadores en materia de protección al consumidor

[6] Cuando el Órgano Resolutivo de Procedimiento Sumarísimo actúa como primera instancia administrativa, es la Comisión de Protección al Consumidor la que actúa como segunda instancia administrativa.

[7] Cabe indicar que el Autor del presente artículo formó parte de la defensa técnica de los denunciados. 
se inician de oficio, ya sea como consecuencia de una denuncia de parte o por propia iniciativa de la autoridad. Ello en concordancia con lo establecido en el artículo 107 del Código y con la Directiva que regula los procedimientos en materia de protección al consumidor previstos en el mencionado Código.

2. La caducidad administrativa no opera de manera automática, tiene que ser determinado por la autoridad.

3. La resolución que declara la caducidad del procedimiento tiene un carácter constitutivo.

El razonamiento que utilizó la Comisión en la mencionada Resolución Final N. ${ }^{\circ}$ 2456-2018/CC2, de fecha 23 de octubre de 2018, fue la siguiente:

67. Lo anterior permite demostrar que con una leve intervención en el ámbito del Principio de Seguridad Jurídica se logra, por otro lado, un grado de satisfacción elevado a favor del Principio de Corrección de la Asimetría, y de la finalidad pública del Estado de defensa del consumidor, principio rector de la economía social de mercado, establecido constitucionalmente en defensa de los derechos del consumidor de acceder a productos y servicios idóneos, encontrándonos ante una restricción legítima que ha superado los umbrales del test de proporcionalidad.

68. Por dichas consideraciones, esta Comisión es de la opinión que la caducidad en los Procedimientos de Protección al Consumidor no opera de manera automática, sino que requiere de un pronunciamiento por parte de la autoridad de Consumo, quien emitirá un acto administrativo aceptando la caducidad administrativa, pronunciamiento que tendrá carácter constitutivo. (Resaltado agregado)

\subsection{Resolución $\mathrm{N} .{ }^{\circ}$ 1079-2019/SPC-INDECOPI}

Mediante la Resolución 1079-2019/SPCINDECOPI, de fecha 24 de abril de 2019, la Sala Especializada en Protección al Consumidor ${ }^{[8]}$ emi- tió la Resolución Final correspondiente al procedimiento de Oficio iniciado en contra de la Empresa de Transportes Miramar S.A; Percy Fernando Rojas Rodríguez; Casimiro Rodríguez Rodríguez; Guillermo Tello Ramírez.

Dicho procedimiento fue iniciado de oficio por la Comisión de la Oficina Regional del INDECOPI en La Libertad, en atención a las presuntas infracciones en el servicio de transporte por parte de los denunciados. Así, con fecha 6 de octubre de 2017 fueron notificados los denunciados con la resolución de inicio del procedimiento administrativo sancionador. Posteriormente, dicha Comisión emitió la Resolución N. ${ }^{\circ}$ 0670-2018/INDECOPI-LAL, el 29 de agosto de 2018, sancionando a la empresa de transportes, al Sr. Rojas y al Sr. Rodríguez. En el recurso de apelación de la empresa de transportes, esta última precisó que al haber transcurrido más de nueve meses desde el inicio del procedimiento hasta la emisión de la resolución, correspondía la aplicación de la Caducidad administrativa.

En Segunda Instancia Administrativa, la Sala Especializada en Protección al Consumidor declaró la caducidad del procedimiento, mediante la Resolución N. ${ }^{\circ}$ 1079-2019/SPC-INDECOPI, ordenando el archivo del procedimiento; sin embargo, realizó la siguiente precisión para la aplicación de la caducidad:

1. Diferencia los procedimientos administrativos sancionadores en materia de protección al consumidor iniciados de oficio y los promovidos a solicitud de parte. Así, identifica que los procedimientos serán de oficio cuando sean del resultado de las actividades de supervisión y fiscalización de la autoridad; mientras que en los procedimientos tramitados por propia iniciativa, los consumidores afectados tienen la posibilidad de presentar su denuncia con la expectativa de ver amparada su pretensión.

2. Conforme a lo anterior, la Sala concluye que la caducidad aplicará para los procedimientos sancionadores iniciados de Oficio, "siendo distinto el caso de los procedimientos iniciados a solicitud de parte, pues es un procedimiento que tiene una naturaleza especial, ya

[8] Como segunda instancia administrativa. 
que el consumidor tiene la expectativa de la tutela por parte de la Administración» (p. 13).

3. En caso de que el procedimiento sea de oficio:

- El procedimiento administrativo sancionador caduca de manera automática a los nueve meses (salvo que se haya ampliado el plazo) de iniciado sin que se notifique la Resolución Final.

- El pronunciamiento por parte de la Administración, que reconoce la caducidad del procedimiento, es declarativo.

\subsection{Resolución N. ${ }^{\circ} 00054-2019 / S D C-I N D E C O P I$}

Mediante la Resolución N. ${ }^{\circ}$ 00054-2019/SDCINDECOPI, de fecha 19 de marzo de 2019, la Sala Especializada en Defensa de la Competencia ${ }^{[9]}$ emitió la Resolución Final correspondiente a la denuncia interpuesta por la Asociación Peruana de Consumidores y Usuarios (ASPEC) en contra FUTURTECNOLOGICAS S.A.C.

Dicho procedimiento fue iniciado por la presunta comisión de actos de competencia desleal por parte de FUTURTECNOLOGICAS. Así, con fecha 28 de setiembre de 2016, la Comisión de Fiscalización de la Competencia Desleal ${ }^{[10]}$ notificó a la denunciada con la resolución de inicio del procedimiento administrativo sancionador; sin embargo, al no notificarse la resolución, el 21 de junio de 2018 la denunciada solicitó la caducidad del procedimiento sancionador.

Con fecha 27 de junio de 2018, la Comisión de Fiscalización de la Competencia Desleal emitió la Resolución N. ${ }^{\circ}$ 0115-2018/CCD-INDECOPI, sancionando a la denunciada. Dicha resolución fue apelada por la denunciada quien indicó que había transcurrido más de 18 meses desde la resolución que dio inicio al procedimiento, por lo que correspondía la aplicación de la caducidad administrativa.

En segunda instancia administrativa, la Sala Especializada en Defensa de la Competencia declaró la caducidad del procedimiento, mediante la Resolución N. ${ }^{\circ}$ 00054-2019/SDC-INDECOPI, ordenando el archivo del procedimiento. Asimismo, realizó la siguiente precisión para la aplicación de la caducidad:

1. Si bien no realizó ninguna precisión sobre los procedimientos iniciados de oficio, al declarar la caducidad el procedimiento promovido por ASPEC, implícitamente está aceptando que los procedimientos administrativos sancionadores son iniciados de oficio, incluso, con la denuncia inicial de un tercero (ASPEC).

2. En atención a que el presente procedimiento fue iniciado antes de la vigencia del Decreto Legislativo 1272, la Comisión contaba con el plazo de un año para emitir su resolución (22 de diciembre de 2017).

3. Pese a que su normativa especial no ha establecido un plazo para la configuración de la caducidad, ha considerado que dicho plazo será el resultado de la sumatoria de cada una de sus etapas procedimentales ${ }^{[11]}$. En ese sentido, para todos aquellos casos posteriores a la vigencia del Decreto Legislativo 1272, le será aplicable dicho plazo ${ }^{[12]}$.

\section{SOBRE LA INTERPRETACIÓN DE LA CADU- CIDAD EFECTUADA POR EL INDECOPI}

Para el análisis del presente documento, hemos verificado la posición del INDECOPI a través

[9] Como órgano de segunda instancia administrativa.

[10] Como órgano de primera instancia administrativa en el procedimiento administrativo sancionador.

[11] Asimismo, dicha entidad hizo mención a la Consulta Jurídica 15-2017/JUS/DGDNCR, de fecha 4 de julio de 2017, emitida por la Dirección General de Desarrollo y Ordenamiento Jurídico del Ministerio de Justicia y Derechos Humanos, en donde se precisó que, si bien la norma de represión de la Competencia Desleal no estableció un plazo determinado para la aplicación de la caducidad, este podía inferirse del periodo dispuesto para cada una de sus etapas procedimentales.

[12] La sumatoria de las diferentes etapas procedimentales asciende a 195 días hábiles. 
de las resoluciones de tres órganos resolutivos distintos, identificando que mantienen cada una un criterio distinto para la aplicación de la caducidad administrativa.

Así, podemos precisar que para el órgano de primera instancia administrativa en protección al consumidor (Comisión de Protección al Consumidor $\mathrm{N}^{\circ}{ }^{2}$ ), no hay distinción en el inicio del procedimiento administrativo, en tanto este siempre será de oficio (ya sea por actividad del propio INDECOPI o por solicitud de parte); dicha posición es compartida por la Sala especializada en Defensa de la Competencia; sin embargo, la Sala Especializada en Protección al Consumidor hace una diferenciación: para los procedimientos iniciados por la supervisión o fiscalización de la autoridad aplicará la caducidad; sin embargo, para los procedimientos «a solicitud de parte» no le sería aplicable la institución de la caducidad.

Asimismo, respecto a la caducidad automática, la Sala Especializada en Protección al Consumidor y la Sala especializada en Defensa de la Competencia admiten que para que se produzca la caducidad es necesario el solo transcurso del tiempo (nueve meses y 195 días hábiles); sin embargo, para la Comisión de Protección al Consumidor $\mathrm{N}^{\circ}{ }^{2}$, ello no es así, estableciendo que es la propia Comisión la que determinará en qué momento otorga (o no) la caducidad. Así, podemos distinguir que, para las Salas especializadas, la resolución que declara la caducidad será declarativa (en tanto la caducidad se produce automáticamente, sin necesidad de la emisión de la resolución), mientras que, para la Comisión, la resolución tiene un carácter constitutivo, en tanto que solo con la emisión de dicha resolución se generaría la caducidad.

Respecto a la legitimidad para declarar o solicitar la caducidad del procedimiento, la Sala Especializada en Protección de Consumidor ha mantenido lo establecido en el Decreto Legislativo 1272, respecto a la declaración de oficio por dicha autoridad o la posibilidad del administrado facultado para solicitar la aplicación de la caducidad. Sin embargo, la Comisión de Protección al Consumidor N ${ }^{\circ}$ 2, considerando la resolución emitida, indica que el administrado legitimado deberá ser el que solicite la caducidad del procedimiento ${ }^{[13]}$.

En ese sentido, podemos resumir los criterios de las Salas y de la Comisión, conforme a lo siguiente:

\begin{tabular}{|l|c|c|c|c|}
\hline $\begin{array}{l}\text { Requisitos de } \\
\text { la Caducidad }\end{array}$ & \multicolumn{1}{|c|}{ D.L 1272 } & $\begin{array}{c}\text { Sala } \\
\text { Especializada } \\
\text { en Defensa de la } \\
\text { Competencia }\end{array}$ & $\begin{array}{c}\text { Sala } \\
\text { Especializada } \\
\text { en Defensa del } \\
\text { Consumidor }\end{array}$ & $\begin{array}{c}\text { Comisión de } \\
\text { Protección al } \\
\text { Consumidor N. } \text { 2 }^{-}\end{array}$ \\
\hline $\begin{array}{l}\text { Tipo de procedi- } \\
\text { mientos }\end{array}$ & $\begin{array}{l}\text { Procedimientos sancio- } \\
\text { nadores iniciados de } \\
\text { oficio }\end{array}$ & TODOS & $\begin{array}{l}\text { Solo los casos ini- } \\
\text { ciados por iniciati- } \\
\text { va de la autoridad }\end{array}$ & TODOS \\
\hline Automático & \multicolumn{1}{|c|}{ Sí } & Sí & $\begin{array}{l}\text { No } \\
\text { (Efecto constitutivo) }\end{array}$ \\
\hline Legitimidad & $\begin{array}{l}\text { Es declaradade oficiopor } \\
\text { el órgano competente. } \\
\text { El administrado se en- } \\
\text { cuentra facultado para } \\
\text { solicitar la caducidad en } \\
\text { caso el órgano compe- } \\
\text { tente no la haya declara- } \\
\text { do de oficio }\end{array}$ & $\begin{array}{l}\text { No hay } \\
\text { precisión }\end{array}$ & Sí & $\begin{array}{l}\text { Debe ser solicitado } \\
\text { por el administrado }\end{array}$ \\
\hline
\end{tabular}

[13] Considerando que, en más de dos años, la Comisión no declaró la caducidad, si no que solo posterior a la solicitud del administrado fue que otorgó la caducidad. 
V. SOBRE LAS CONSIDERACIONES ESPECÍFICAS APLICABLES A LA NORMATIVA DE PROTECCIÓN AL CONSUMIDOR Y DE COMPETENCIA DESLEAL

Realizado el resumen de los criterios emitidos por el INDECOPI, corresponde plantear aquellas circunstancias que no fueron planteadas o que, como mínimo, hace que nos cuestionemos el contenido de las resoluciones y los criterios que viene manejando dicha entidad sobre la figura de la caducidad administrativa.

\subsection{Sobre las Consideraciones de la Comisión de Protección al Consumidor $\mathrm{N} .^{\circ} 2$}

Como ya ha sido explicado, la figura de la caducidad es una institución que busca el equilibrio entre la potestad sancionadora del Estado y el derecho del administrado a contar con la seguridad jurídica que en un procedimiento administrativo sancionador este será resuelto en un plazo razonable, eliminando la situación de incertidumbre.

Para que esta situación se cumpla, el Decreto Legislativo 1272 estableció que el plazo general para el desarrollo de un procedimiento administrativo sancionador sería de nueve meses (ampliable por tres meses más), siendo que si la autoridad encargada del procedimiento no cumplía con notificar la Resolución final en dicho plazo automáticamente se produciría la caducidad del procedimiento.

Sin embargo, pese a que la norma explícitamente establece que la caducidad se genera de manera automática, la Comisión ha establecido una «nueva caducidad», indicando que esta no es automática, contrario a lo establecido en la doctrina extranjera y a los fundamentos de dicha figura, estableciendo que la misma se producirá cuando se emita la resolución que la declare, es decir la resolución tendrá un carácter constitutivo.

Sobre lo anterior, en la figura de la caducidad introducida por el Decreto Legislativo N. ${ }^{\circ} 1272$, la caducidad se produce por el simple paso del tiempo, por lo que la resolución que declare la caducidad del procedimiento tendrá un carácter declarativo (la caducidad ya se generó); sin embargo, como ya se indicó, la Comisión ha "creado» una nueva caducidad, que no se genera de manera automática, la cual se cumple únicamente cuando la Comisión lo determine. En ese sentido, cabe preguntarnos ¿qué seguridad se le garantiza al administrado? Esta nueva caducidad, ¿otorga seguridad jurídica a los administrados que se encuentran en un procedimiento sancionador seguido ante la Comisión?

Finalmente, el Decreto Legislativo N. ${ }^{\circ} 1272$ estableció que la caducidad debía ser declarada de oficio por la autoridad (en este caso, la Comisión $\mathrm{N} .^{\circ}$ 2) y que, a su vez, podía ser solicitada por el administrado. Sin embargo, de la revisión del criterio de la Comisión, en más de dos años dicho órgano no declaró la caducidad, solo con la solicitud de los denunciados para la aplicación de la caducidad fue que se otorgó la misma, por lo que concluimos que nuevamente la Comisión modificó la figura de la caducidad, al negar la obligación que tenían de emitir de oficio la caducidad del procedimiento, siendo que en todos los casos los administrados tendrán que solicitar la caducidad, a efectos que la Comisión cumpla con declarar la misma.

En ese sentido, resulta necesario señalar que el criterio emitido por la Comisión es contrario a lo que justamente busca la institución de la caducidad, toda vez que, bajo el criterio utilizado por la Comisión, un procedimiento administrativo sancionador podría llegar a durar años, sin que la autoridad tenga limitación alguna a su potestad sancionadora, pues al establecer el carácter "constitutivo» de la Caducidad, es la Comisión la que podrá determinar cuándo desea que deba operar la caducidad, lo cual, consideramos es contrario, a la finalidad que tiene dicha institución: la seguridad jurídica de todos los administrados.

\subsection{Sobre las consideraciones de la Sala Espe- cializada en Protección al Consumidor}

Para la Sala especializada, la institución de la caducidad se aplicará únicamente para aquellos procedimientos administrativos sancionadores iniciados de oficio, mientras que aquellos que fueron «promovido de parte» no les será aplicable dicha figura.

Al respecto, cabe mencionar que el Código de Protección y Defensa del Consumidor (artículo 107), establece lo siguiente: 
Artículo 107. Postulación del procedimiento

Los procedimientos administrativos para conocer las presuntas infracciones a las disposiciones contenidas en el presente Código se inician de oficio, bien por propia iniciativa de la autoridad, por denuncia del consumidor afectado o del que potencialmente pudiera verse afectado, o por una asociación de consumidores en representación de sus asociados 0 poderdantes o en defensa de intereses colectivos o difusos de los consumidores. En este último caso, la asociación de consumidores actúa como tercero legitimado sin gozar de las facultades para disponer derechos de los consumidores afectados, salvo de sus asociados o de las personas que le hayan otorgado poder para tal efecto. Tanto el consumidor constituido como parte como el tercero legitimado pueden participar en el procedimiento e interponer los recursos contra la resolución que deniegue el inicio del procedimiento y contra cualquier otra resolución impugnable que les produzca agravio. El procedimiento administrativo en materia de protección al consumidor se inicia con la notificación de la imputación de cargos al posible infractor. (Subrayado añadido)

De acuerdo a lo anterior, todos los casos de protección al consumidor, independientemente de la forma en que se inicien, son catalogados por el propio Código del Consumidor como procedimientos de oficio. Así, para que la Sala llegue a la conclusión de que la figura de la caducidad únicamente es aplicable a los casos iniciados por la propia autoridad debería modificarse el mencionado artículo. Mientras tanto debe considerar lo señalado en el propio Código.

En efecto, lo relevante no es cómo se inició el procedimiento, lo verdaderamente importante es que la caducidad es un «castigo» para la administración pública, que no ejerce su potestad sancionadora en el plazo fijado por el Decreto Legislativo 1272. Caso contrario, como ha venido haciendo la Sala, distingue circunstancias que la ley no diferencia, lo cual deviene en una transgresión de la normativa.

\subsection{Sobre las consideraciones de la Sala Espe- cializada en Defensa de la Competencia}

La Sala especializada no hace ninguna interpretación sobre la aplicación o no de la caducidad por el «tipo» de inicio del procedimiento administrativo sancionador; tampoco modifica el carácter declarativo de la resolución que declara la caducidad o impone algún gravamen adicional.

La Sala indica que su procedimiento Administrativo Sancionador tiene una duración de 195 días hábiles, resultado de la sumatoria de sus plazos establecidos para cada una de las etapas procedimentales previstas en el Decreto Legislativo $\mathrm{N} .{ }^{\circ}$ 1044, por lo que únicamente si verifica que en la primera instancia transcurre más de dicho plazo para que emita la Resolución final de algún procedimiento sancionador a su cargo, corresponderá que se declare la caducidad del procedimiento.

Al respecto, de la revisión del Decreto Legislativo $\mathrm{N} .^{\circ} 1044$ se verifica que en ningún momento se utiliza el término de caducidad, ni tampoco contempla alguna disposición por la cual se pueda desprender, de manera directa o indirecta, alguna consecuencia respecto del incumplimiento de los plazos establecidos en dicha norma.

Asimismo, de la revisión de la Consulta Jurídica 15-2017/JUS/DGDNCR, de fecha 4 de julio de 2017, sustento de la Sala, verificamos que se limita a precisar que el Decreto Legislativo N. ${ }^{\circ} 1034$ (Ley de Represión de las prácticas anticompetitivas) tiene un plazo de caducidad sin ofrecer la justificación de la misma. Así, realiza la "suma» de las etapas procedimentales para concluir que dicho plazo será el plazo máximo para resolver, de lo contrario se producirá la caducidad, pese a que no justifica el motivo de dicho razonamiento.

Adicionalmente, al revisar la Ley del Procedimiento Administrativo General (con las modificaciones introducidas por el Decreto Legislativo 1272) no se verifica que como consecuencia del incumplimiento de los plazos procedimentales de un procedimiento administrativo sancionador ocasione la conclusión de dicho procedimiento.

En ese sentido, consideramos que, para la aplicación de la caducidad en un procedimiento ad- 
ministrativo sancionador, la determinación del plazo legal no puede ni debe estar sujeta a consideraciones subjetivas, todo lo contrario, debe venir expresamente determinada por ley.

En ese sentido, al verificar que no existe un plazo especial para la caducidad en el procedimiento sancionador previsto en el Decreto Legislativo 1044, consideramos que le es aplicable el régimen general, esto es el régimen de caducidad establecido en la Ley del procedimiento Administrativo General.

\section{CONCLUSIONES FINALES}

El Decreto Legislativo N. ${ }^{\circ} 1272$ introdujo la institución de la caducidad administrativa, a efectos de lograr un equilibrio entre administrados y la entidad administrativa sancionadora. Así, estableció un régimen general para la aplicación de dicha institución, permitiendo que los regímenes especiales establezcan plazos distintos a dicho régimen general.

En estas disposiciones, de carácter general, se dispuso que en los procedimientos administrativos sancionadores que tuviesen una tramitación mayor a nueve meses ${ }^{[14]}$ sin que se notifique la Resolución Final, se produciría la caducidad administrativa, lo cual implicaba el archivo del procedimiento administrativo sancionador.

Asimismo, se estableció que esta figura era aplicable a los procedimientos sancionadores de oficio, que la caducidad se producía de manera automática y que el órgano correspondiente tenía el deber de emitir de oficio la resolución que declarase la caducidad del procedimiento.

Así, las reglas claras, resulta educativo verificar cómo el INDECOPI, una entidad técnica y especializada, que se caracteriza por su independencia y labor académica, también ha mantenido diferentes «interpretaciones» de lo que parecía una figura clara de aplicar.

Así, tenemos que la Comisión de Protección al Consumidor $\mathrm{N} .{ }^{\circ} 2$ «creó» una nueva caducidad, la cual no cumple con el propósito de generar la seguridad jurídica del administrado; modificando incluso la característica esencial de la caducidad: la penalización por el paso del tiempo sin actuaciones de la autoridad, en tanto sería la propia Comisión la que determinaría en qué momento se generaría la caducidad (si es que lo determinaba).

Asimismo, la Sala Especializada en Protección al Consumidor, realizó una diferenciación entre los procedimientos de oficio (donde aplicaría la caducidad) y los procedimientos iniciados a solicitud de parte (donde no aplicaría), pese a que la misma norma (Código de protección y Defensa del Consumidor) establece explícitamente que todos los procedimientos sancionadores son de oficio (ya sea iniciados por la autoridad o por solicitud de parte).

Incluso, la Sala Especializada de Defensa de La Competencia, que cumplió con las reglas generales (Resolución Declarativa, legitimidad para declarar o solicitar la caducidad y transcurso del tiempo como único requisito para que se constituya la caducidad), aplica un plazo mayor para la generación de la caducidad, pese a que su norma especial no establezca expresamente dicha condición ${ }^{[15]}$.

En ese sentido, resulta pertinente preguntarnos si verdaderamente el INDECOPI ha entendido cuál es la finalidad de la caducidad en el procedimiento administrativo sancionador, sí se ha olvidado que existe un administrado que merece seguridad jurídica sobre el plazo poco razonable que se toma la administración para emitir un pronunciamiento. Asimismo, recordarle que el Decreto Legislativo N. ${ }^{\circ}$ 1272 indicó que era posible que los procedimientos especiales fijasen otro plazo (distinto de los nueve meses), en a tención a la complejidad de la materia analizada; sin embargo, el INDECOPI, lejos de promover las modificaciones necesarias a las normativas de protección al consumidor o de represión de la competencia desleal que considerase necesarias, ha buscado realizar «interpretaciones» a la normativa para así concluir, por ejemplo, que donde dice

[14] Dicho plazo sería ampliable por tres meses más, siempre que dentro de los primeros nueve meses se emita una resolución que justifique la ampliación por tres meses más.

[15] En este supuesto, la Sala se guio de lo indicado por el Ministerio de Justicia, por lo que es entendible su posición. 
que es automático, concluir que no es automático, donde dice nueve meses dice plazo indeterminado, y entre otros ejemplos. Es momento que el INDECOPI asuma el rol técnico que lo ha caracterizado y aplique la figura de la caducidad sin cometer estas «interpretaciones auténticas».

\section{REFERENCIAS BIBLIOGRÁFICAS}

Baca Oneto, V. (2011). La Prescripción de las Infracciones y su Clasificación en la Ley del Procedimiento Administrativo General. Derecho \& Sociedad 37.

Caballero Sánchez, R. (1999). Prescripción y Caducidad en el ordenamiento administrativo. Madrid: McGrawhill.

(2010). Procedimiento sancionador: caducidad en Diccionario de sanciones administrativas. Madrid: lustel.

Comisión de protección al Consumidor N. ${ }^{\circ} 2$. (23 de octubre de 2018). Resolución Final $N .^{\circ} 2456$ 2018/CC2

Congreso de la República. (2 de setiembre de 2010). Código de Protección y Defensa del Consumidor. Ley 29571.
Gonzales Navarro, F. y Gonzales Pérez. (2012). Comentarios a la Ley de régimen jurídico de las administraciones públicas y procedimiento administrativo común. Madrid: Civitas.

González Pérez, J. (2002). Manual de Procedimiento Administrativo. Civitas.

Ministerio de Justicia. (2017). Guía práctica sobre el procedimiento administrativo sancionador. Lima.

Presidencia de la República. (21 de diciembre de 2016). Decreto Legislativo que modifica la Ley $\mathrm{N}^{\circ}{ }^{\circ} 27444$, Ley del Procedimiento Administrativo General y deroga la Ley N. ${ }^{\circ} 29060$, Ley del Silencio Administrativo. Decreto Legislativo 1272.

Presidencia de la República. (26 de junio de 2008). Decreto Legislativo que aprueba la Ley de Represión de la Competencia Desleal.

Sala especializada en Protección al Consumidor. (24 de abril de 2019). Resolución $N^{\circ}{ }^{\circ}$ 10792019/SPC-INDECOPI

Sala especializada en Defensa de la Competencia. (19 de marzo de 2019). Resolución N. ${ }^{\circ} 00054-$ 2019/SDC-INDECOPI 